\title{
Conditioning the entomopathogenic nematodes Steinernema carpocapsae and Heterorhabditis megidis by pre-application storage improves efficacy against black vine weevil, Otiorhynchus sulcatus (Coleoptera: Curculionidae) at low and moderate temperatures
}

\author{
Adam Guy a,b, Michael Gaffney ${ }^{\mathrm{b}}$, Apostolos Kapranas ${ }^{\mathrm{c}}$, Christine T. Griffin ${ }^{\mathrm{a}, *}$ \\ ${ }^{a}$ Department of Biology, Maynooth University, Maynooth, County Kildare, Ireland \\ ${ }^{\mathrm{b}}$ Horticulture Development Department, Teagasc, Ashtown, Dublin 15, Ireland \\ ${ }^{\mathrm{c}}$ FARCE Lab, Institute of Biology, University of Neuchâtel, Emile-Argand 11, 2000 Neuchâtel, Switzerland
}

\section{H I G H L I G H T S}

- Efficacy of $H$. megidis and S. carpocapsae is improved by storage at $9{ }^{\circ} \mathrm{C}$ for 3-6 weeks.

- Efficacy is improved across a range of test conditions, both above and below $9{ }^{\circ} \mathrm{C}$.

- $9{ }^{\circ} \mathrm{C}$-stored $H$. megidis kill more vine weevil larvae than S. kraussei in winter.

- $9^{\circ} \mathrm{C}$ storage of $H$. megidis compensates for lower application rate against vine weevil.

- Success of $S$. kraussei is strongly influenced by vine weevil instar.

\section{A R T I C L E I N F O}

\section{Article history:}

Received 26 August 2016

Revised 8 February 2017

Accepted 10 February 2017

Available online 13 February 2017

\section{Keywords:}

Conditioning

Entomopathogenic nematodes

Application rate

Otiorhynchus sulcatus

Larval instar

\begin{abstract}
A B S T R A C T
Entomopathogenic nematodes (Heterorhabditis spp. and Steinernema spp.) are effective biocontrol agents for several insect pests, but their use is restricted by environmental constraints such as temperature and by their high cost. Use of nematodes against vine weevil (Otiorhynchus sulcatus) is restricted by low temperatures prevailing at the time when control is required. Here we investigate the potential for "conditioning" - storing nematode infective juveniles at $9{ }^{\circ} \mathrm{C}$ for at least three weeks prior to application - to improve efficacy, both at low and moderate temperatures. Conditioned Heterorhabditis megidis were previously shown to give improved control of vine weevil when applied to potted plants at constant $9{ }^{\circ} \mathrm{C}$ Here we show similar results for Steinernema carpocapsae conditioned for $3-6$ weeks at $9{ }^{\circ} \mathrm{C}$. We also show that conditioning ( 3 weeks pre-application storage at $9{ }^{\circ} \mathrm{C}$ ) improved efficacy of both species against vine weevil in strawberries grown in bags in an unheated glasshouse at $0-12^{\circ} \mathrm{C}$. In a final experiment, we also test whether improved performance of $9{ }^{\circ} \mathrm{C}$-stored $\mathrm{H}$. megidis compensates for a reduced application rate at a more permissive temperature, $15^{\circ} \mathrm{C}$. Conditioned $\mathrm{H}$. megidis gave control equal to that of unstored $H$. megidis applied at double the rate. Commercial product based on the cold-active species Steinernema kraussei was used as a reference treatment in all experiments. At constant $9{ }^{\circ} \mathrm{C}, \mathrm{S}$. kraussei gave control superior to that of both unstored and conditioned $H$. megidis and $S$. carpocapsae, while at constant $15^{\circ} \mathrm{C}$, both conditioned and unstored $H$. megidis applied at half the recommended rate gave superior control to S. kraussei applied at full rate. Repetition of experiments with vine weevil larvae of increasing age indicated that success of $S$. kraussei is more influenced by larval age than that of the other two species, and that this species is more effective against younger (2nd-3rd) than older (4th-7th) instars.
\end{abstract}

(c) 2017 Elsevier Inc. All rights reserved.

\footnotetext{
* Corresponding author.

E-mail address: christine.griffin@nuim.ie (C.T. Griffin).
}

\section{Introduction}

The entomopathogenic nematodes (EPN) Steinernematidae and Heterorhabditidae are widely used as biological control agents. 
Several species of Steinernema and Heterorhabditis are produced in bioreactors and infective juveniles (IJs) are applied inundatively against a number of pests (Georgis et al., 2006; Lacey et al., 2015). They have many attributes that make them attractive for pest control, including environmental safety and active hostsearching that allows them to seek out pests in the root zone and other cryptic habitats. Factors that limit their use include relatively high cost and sensitivity to environmental conditions (Georgis et al., 2006; Shapiro-Ilan et al., 2006). Various approaches have been taken to overcome these limitations, such as discovery of superior species or strains and genetic improvement through hybridization, selection and genetic manipulation (Bal et al., 2014; Griffin and Downes, 1994; Nimkingrat et al., 2013; Salame et al., 2014). In addition to genetic quality, however, physiological condition of the IJs may also affect their performance. Typically, IJ quality declines over time, but there is evidence for several species that their ability to infect and kill insects may initially improve, under certain storage conditions, before the inevitable deterioration (Fan and Hominick, 1991; Griffin, 1996; Koppenhöfer et al., 2013). Following on from laboratory assays which showed that particular conditions of storage temperature and duration resulted in increased infectivity of Heterorhabditis megidis (Poinar, Jackson and Klein) (Griffin, 1996), Fitters et al. (2001) showed that storing $H$. megidis IJs in aqueous suspension at $9{ }^{\circ} \mathrm{C}$ for up to 12 weeks resulted in improved control of black vine weevil, Otiorhynchus sulcatus (Fabricius), at $9^{\circ} \mathrm{C}$.

Black vine weevil is an important pest of soft fruits (such as strawberries and blackcurrants), ornamental plants and hardy ornamental nursery stock in many parts of the world (Moorhouse et al., 1992). Adult weevils feed on the foliage which can result in cosmetic damage, but the main damage is due to larvae feeding on roots. Primarily, eggs are laid in late summer/ autumn, and larval development and activity can occur at temperatures as low as $6{ }^{\circ} \mathrm{C}$ (Smith, 1932; Stenseth, 1979), with next generation adults emerging in early summer of the following year. Nematodes applied to growing media can give effective control, but low temperature is the major factor limiting their success (Georgis et al., 2006; Lacey et al., 2015; van Tol and Raupp, 2005). While most species such as $H$. megidis do not work well below $12-14{ }^{\circ} \mathrm{C}$, Steinernema kraussei (Steiner) is recognized as a cold-active species, capable of controlling vine weevil at lower temperatures (Long et al., 2000; Willmott et al., 2002) and is currently marketed for this purpose. Other factors influencing the efficacy of EPN against vine weevil include host plant and the developmental stage of the insect (van Tol and Raupp, 2005).

The objectives of this work are (1) to test whether low temperature performance of Steinernema carpocapsae (Weiser), one of the most widely used nematode species, can be improved by storing IJs at $9{ }^{\circ} \mathrm{C}$, as was previously shown for $H$. megidis by Fitters et al. (2001); (2) Test whether the effect of conditioning, previously demonstrated by Fitters et al. for $\mathrm{H}$. megidis in potted ornamentals at $9{ }^{\circ} \mathrm{C}$ under controlled conditions, can also be detected more generally. The effect of conditioning is tested both under more challenging conditions (strawberries in grow-bags in an unheated greenhouse), for both species, and under more permissive conditions (potted ornamentals at constant $15^{\circ} \mathrm{C}$ ), for $\mathrm{H}$. megidis only, and (3) to ascertain whether improved performance of $9^{\circ} \mathrm{C}$ stored $H$. megidis compensates for a reduced application rate at the permissive temperature, $15^{\circ} \mathrm{C}$. Commercially produced $S$. kraussei (Nemasys L) was used as a reference treatment in all experiments. The selection of $9^{\circ} \mathrm{C}$ as the conditioning temperature was based on extensive bioassays showing that $9-12{ }^{\circ} \mathrm{C}$ was consistently better than higher or lower storage temperatures (Guy, Gaffney and Griffin, unpublished data).

\section{Materials and methods}

\subsection{Nematodes and insects}

S. carpocapsae and $H$. megidis were obtained from BASF (formerly Becker Underwood), Littlehampton, UK as Nemasys C and Nemasys $\mathrm{H}$, respectively. They were subsequently maintained in the laboratory and reared for experiments in larvae of Galleria mellonella $\mathrm{L}$. (greater wax moth, obtained from the Mealworm Company, Sheffield, UK) at $20^{\circ} \mathrm{C}$ using standard methods (Woodring and Kaya, 1988). Harvested IJs were washed 3 times by sedimentation in tap water, and were either used immediately (unstored) or were stored in tap water at $9{ }^{\circ} \mathrm{C}$ for 3 or 6 weeks before use. Storage was at a density of $1000 \mathrm{IJ} / \mathrm{ml}$, in $9 \mathrm{~cm}$ diam. plastic food tubs with snap-on lids each containing $25 \mathrm{ml}$ of nematode suspension. Steinernema kraussei (Nemasys L) was obtained from BASF UK and formulated product was kept at $4{ }^{\circ} \mathrm{C}$ for up to a week prior to use in experiments. Otiorhynchus sulcatus eggs were collected from adult weevils maintained in the laboratory on Taxus baccata L. cut foliage.

2.2. Experiments 1 and 2: Control of $O$. sulcatus larvae in potted plants at $9{ }^{\circ} \mathrm{C}$ by $\mathrm{S}$. carpocapsae and $\mathrm{H}$. megidis previously stored at $9{ }^{\circ} \mathrm{C}$ for up to 6 weeks

In experiment $1, S$. carpocapsae was tested on polyanthus plants (Primula polyantha Mill.; Syngenta) while in experiment 2, H. megidis was tested on begonia (Begonia $x$ semperflorens-cultorum hort. mix; Syngenta). The choice of plant was dependent on availability. Plug plants of polyanthus were potted into $9 \mathrm{~cm}$ liners filled with multi-purpose compost (Forker Garden Products, Portadown, Northern Ireland). Begonia plants were potted into $13 \mathrm{~cm}$ diameter circular pots. In each liner or pot, 20 vine weevil eggs were buried at a depth of $2 \mathrm{~cm}$ in the compost surrounding the plant. The plants were kept in an unheated glasshouse for at least 5 (exp. 1 ) or 7 (exp. 2) weeks to allow weevil larvae to develop, and were moved to a growth room 7 days prior to nematode application.

In each experiment there were five treatments, applied on the same day: the focal species (either S. carpocapsae or H. megidis) which had newly emerged from $G$. mellonella cadavers (unstored); the focal species which had been stored at $9^{\circ} \mathrm{C}$ for 3 weeks prior to application; the focal species stored at $9{ }^{\circ} \mathrm{C}$ for 6 weeks; commercially produced $S$. kraussei, and a control where only water was applied. In experiment $1,3600 \mathrm{~S}$. carpocapsae IJ in $37 \mathrm{ml}$ tap water was applied to the soil surface. Control plants received $37 \mathrm{ml}$ of tap water. In experiment $2,6500 \mathrm{H}$. megidis $\mathrm{IJ}$ in $49 \mathrm{ml}$ tap water were applied to each plant, and $49 \mathrm{ml}$ of tap water applied to each control plant. Application rates were based on recommended rates for Nemasys L.

Each experiment was conducted four times, at 3-week intervals. In each run there were 15 plants per treatment. The stage of the vine weevil larvae (based on head capsule size) (Gaffney, 2012) was assessed at time of treatment by destructive sampling of additional plants. In experiment 1 , the larvae were at instars $2-3,3-4$, 4-5 and 6-7, respectively, in the four runs A-D, and in experiment 2 they were at instars $3-4,4-5,5-6$ and $6-7$, respectively. Plants were incubated in a growth room (L:D 16:8 h) with soil temperature of $9{ }^{\circ} \mathrm{C}$, and watered regularly. After 28 days the plants were destructively sampled and the number of live insects was counted.

\subsection{Experiment 3: Control of 0 . sulcatus larvae in bagged strawberry} plants in an unheated glass house $\left(0-12^{\circ} \mathrm{C}\right)$ by S. carpocapsae and $\mathrm{H}$. megidis that had previously been stored at $9^{\circ} \mathrm{C}$

Module grown strawberry (Fragaria $\times$ ananassa Duchesne) runners 'Elsanta' (McCarthys Fruit Farm, Ireland) were transplanted 
into $20 \mathrm{~L}$ strawberry peat module bags (Clonbrin Peat Products, Clonbrin, Ireland) in an unheated glasshouse. Three plants were transplanted at equal distances down the centre of each bag. The plants were allowed to re-establish for 4 weeks, being treated with liquid nutrients twice a week for the first 3 weeks. Following this, 200 . sulcatus eggs were buried at a depth of $2-3 \mathrm{~cm}$ in the peat surrounding each plant. Since there were three plants in each strawberry bag, each bag received a total of 60 eggs. The plants were then left in the unheated glasshouse to allow the insects to develop.

There were six treatments, applied on the same day: unstored $S$. carpocapsae (newly emerged from G. mellonella cadavers); S. carpocapsae stored at $9{ }^{\circ} \mathrm{C}$ for 3 weeks prior to application; unstored $H$. megidis; $H$. megidis stored at $9{ }^{\circ} \mathrm{C}$ for 3 weeks; commercially produced $S$. kraussei, and a control where only water was applied. Nematodes (25,000 IJs in $50 \mathrm{ml}$ water) were applied to the soil surface around each strawberry plant. To each control plant, $50 \mathrm{ml}$ of tap water was applied. This experiment was conducted only once, during January-February 2012. There were 15 replicate bags (containing a total of 45 strawberry plants) per treatment. The 0 . sulcatus larvae present were 5th-7th instars at the time of nematode application. The bags were incubated in the glasshouse for 2834 days at which time they were destructively sampled and all live insects per bag were counted.

Both the temperature within the strawberry peat bags and the ambient temperature were recorded every 10 min during trials using Tinytag dataloggers (Gemini Data Loggers, West Sussex, UK). Two sensors were buried at a depth of $5 \mathrm{~cm}$ in the peat, and two were placed at the height of the top of the plants to record ambient air temperature. The temperature fluctuated over the course of the experiment, but did not exceed $12^{\circ} \mathrm{C}$ in the peat of the grow-bags. For the first two weeks of the experiment, the temperature in the peat fluctuated around $10^{\circ} \mathrm{C}$ (ranging $8-12^{\circ} \mathrm{C}$ ) then dropped to below $8^{\circ} \mathrm{C}$, only rising again towards the end of the experiment.

2.4. Experiment 4: Control of O. sulcatus in potted Cyclamen plants at $15{ }^{\circ} \mathrm{C}$ by stored and unstored $\mathrm{H}$. megidis at reduced application rate

Cyclamen (Cyclamen persicum Mill.) plug-plants (Syngenta) were potted into $13 \mathrm{~cm}$ circular pots filled with multi-purpose compost (Forker Garden Products, Portadown, Northern Ireland). In each pot, 200 . sulcatus eggs were placed at a depth of $2 \mathrm{~cm}$ in the compost surrounding the plant. The plants were then placed in an unheated glasshouse to allow the weevils to develop. Plants were moved to a growth room (L:D $16: 8 \mathrm{~h}, 15^{\circ} \mathrm{C}$ within the compost) 7 days prior to nematode application.

There were six treatments, applied on the same day: four $H$. megidis treatments, S. kraussei applied at $6500 \mathrm{IJ}$ per plant $(100 \%$ recommended rate), and a control. The $H$. megidis treatments were unstored IJs (newly emerged from G. mellonella cadavers) applied at $3250 \mathrm{IJ}$ per plant (50\% recommended rate); unstored $\mathrm{H}$. megidis applied at $1623 \mathrm{IJ}$ per plant (25\% recommended rate); $H$. megidis stored at $9{ }^{\circ} \mathrm{C}$ for 3 weeks and applied at $3250 \mathrm{IJ}$ per plant and $H$. megidis stored at $9{ }^{\circ} \mathrm{C}$ for 3 weeks and applied at $1623 \mathrm{IJ}$ per plant. Nematodes were applied in $49 \mathrm{ml}$ of tap water, while each control plant received $49 \mathrm{ml}$ of tap water.

The experiment was conducted twice. In each run, there were 12 pots per treatment. For the first and second runs, the weevil larvae were 4 th-6th and 6th-7th instars respectively at the time of nematode application. Plants were watered regularly in the $15^{\circ} \mathrm{C}$ growth room, and 28 days after nematode application they were destructively sampled and a count was made of live insects.

\subsection{Statistics}

We generally used Generalized Linear Models to assess how the number of live larvae was influenced by treatment and run (exper- iments 1, 2 \& 4). For experiments 1,2 and 4 where small counts (number of larvae) were analyzed we used a quasi-Poisson error variance, which corrects for potential over- or under-dispersion (Crawley, 1993). After rescaling, the significance of each explanatory variable (treatment and run) was assessed by the change in deviance when it was removed from the model in stepwise fashion. Post hoc tests were performed using a least Square Difference Test at $\alpha=0.05$. In experiment 3 , data were normally distributed and thus we applied a 1-way ANOVA with a Tukey's post hoc test among treatments $(\alpha=0.05)$.

\section{Results}

3.1. Experiments 1 and 2: Control of Otiorhynchus sulcatus larvae in potted plants at $9{ }^{\circ} \mathrm{C}$ by S. carpocapsae and $H$. megidis previously stored at $9{ }^{\circ} \mathrm{C}$ for up to 6 weeks

\subsubsection{Experiment 1}

Treatment had a significant effect on the number of live larvae at the end of the trial $\left(\mathrm{F}_{4,280}=37.65, \mathrm{P}<0.001\right)$ but run did not ( $\left.F_{3,280}=1.28, P=0.281\right)$; however, run was significant via its significant interaction with treatment $\left(\mathrm{F}_{12,280}=2.44, \mathrm{P}<0.01\right)$, therefore the results of each run are plotted separately (Fig. 1). Unstored $S$. carpocapsae failed to reduce the number of live vine weevil larvae infesting polyanthus over 4 weeks at $9{ }^{\circ} \mathrm{C}$ : in each of the 4 runs of the experiment, treated and untreated pots harbored equal numbers of larvae (Fig. 1). When the nematodes had been stored for 3 or 6 weeks at $9{ }^{\circ} \mathrm{C}$, numbers of live larvae differed significantly to the control in each run, with the number present reduced by $35-61 \%$. However, the performance of S. kraussei generally exceeded that even of the conditioned $S$. carpocapsae, with numbers reduced relative to control by $93,83,55$ and $55 \%$ in runs A-D, respectively (Fig. 1). A trend can be noted in that the number of live larvae in the $S$. kraussei treatment showed a sustained increase over the four runs of the experiment, corresponding to an increase in the age of $O$. sulcatus larvae at the time of nematode application. Thus, in the later runs ( $C$ and $D$ ) there was no significant difference between $S$. kraussei and $S$. carpocapsae stored for either 3 or 6 weeks (Fig. 1).

\subsubsection{Experiment 2}

Treatment had a significant effect on number of live larvae infesting begonia after 4 weeks at $9{ }^{\circ} \mathrm{C}\left(\mathrm{F}_{4,280}=21.18, \mathrm{P}<0.001\right.$, Fig. 2) but run did not $\left(\mathrm{F}_{3,280}=0.70, \mathrm{P}=0.552\right)$. The interaction between treatment and run was not significant $\left(F_{12,280}=0.32\right.$, $\mathrm{P}=0.985$ ). The pattern in this experiment with $H$. megidis was similar to that found in experiment 1 with $S$. carpocapsae: plants treated with unstored $H$. megidis had as many live weevil larvae as the controls, while in plants treated with $H$. megidis that had been stored for 3 or 6 weeks prior to application the number of live larvae differed significantly to the control (reduced by 33 and $36 \%$, respectively). However, plants treated with $S$. kraussei had fewer larvae than those treated with stored $H$. megidis, and a $56 \%$ reduction relative to control (Fig. 2).

3.2. Experiment 3: Control of Otiorhynchus sulcatus larvae in bagged strawberry plants in an unheated glass house $\left(0-12^{\circ} \mathrm{C}\right)$ by $S$. carpocapsae and $\mathrm{H}$. megidis that had previously been stored at $9^{\circ} \mathrm{C}$

Differences between treatments in numbers of live weevil larvae infesting strawberry plants were significant $\left(F_{5,89}=7.949\right.$, $\mathrm{P}<0.001)$. Unstored $S$. carpocapsae or $H$. megidis failed to reduce the number of larvae relative to the control during 4 weeks in an unheated greenhouse (Fig. 3), while S. carpocapsae or H. megidis that had previously been stored at $9{ }^{\circ} \mathrm{C}$ effected a reduction of 19 


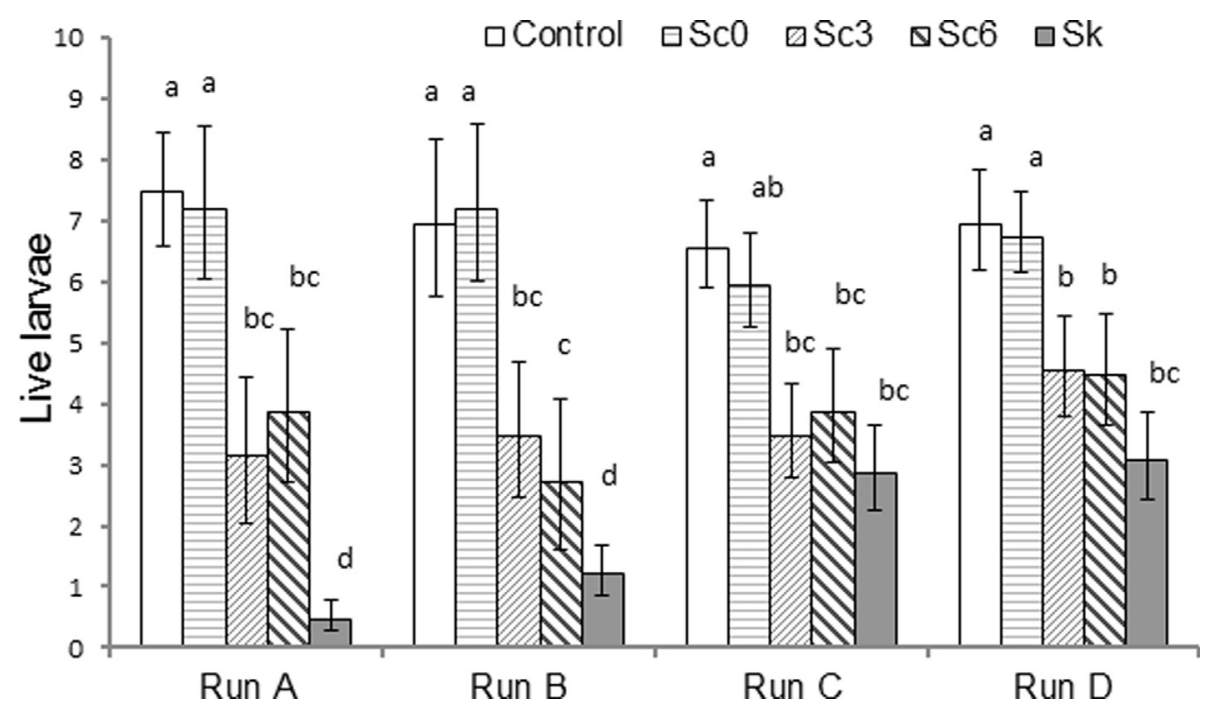

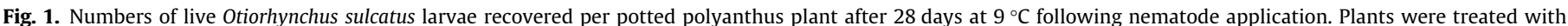

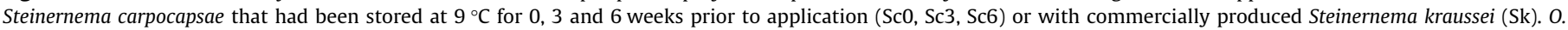

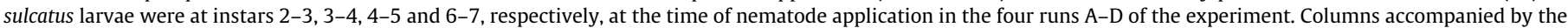
same letter are not significantly different (Least squares difference test, $\alpha=0.05$ ).

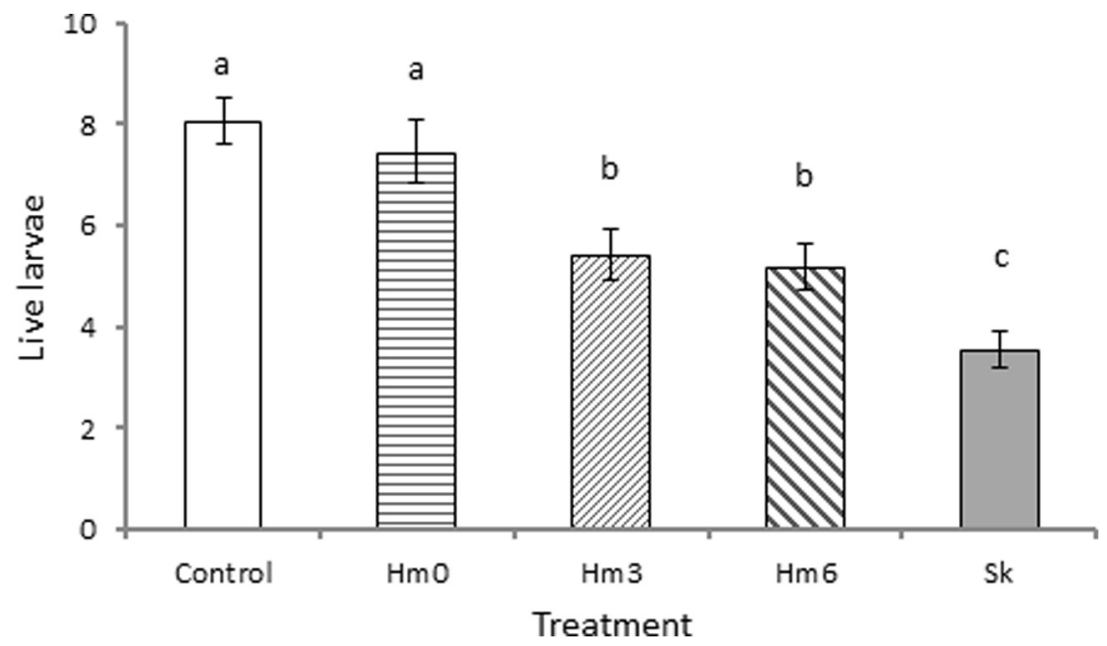

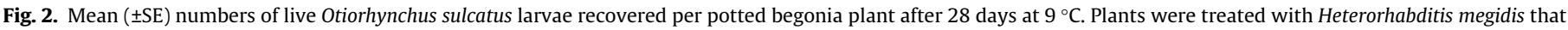

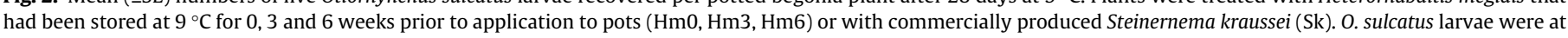

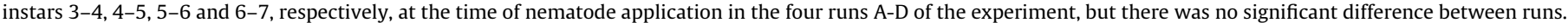
Columns accompanied by the same letter are not significantly different (Least squares difference test, $\alpha=0.05$ ).

and $32 \%$, respectively, relative to the control. In this experiment, 3week stored $H$. megidis were superior in performance to $S$. kraussei, with a significant difference in number of live larvae between the two treatments (Fig. 3).

3.3. Experiment 4: Control of O. sulcatus in potted Cyclamen plants at $15{ }^{\circ} \mathrm{C}$ by stored and unstored $H$. megidis at reduced application rate

Treatment had a significant effect on number of larvae alive at the end of the trial $\left(F_{5,132}=30.7, P<0.001\right.$, Fig. 4) but run did not $\left(F_{1,132}=0.75, P=0.387\right)$. The interaction between treatment and run was not significant $\left(\mathrm{F}_{5,132}=0.20, \mathrm{P}=0.963\right)$. In this experiment which was conducted at $15^{\circ} \mathrm{C}$, all nematode treatments differed to the control (Fig. 4). Unstored $H$. megidis at $25 \%$ application rate performed as well as $S$. kraussei at full application rate, with reductions of 55 and $54 \%$, respectively, in number of live weevil larvae relative to the control (Fig. 4). There was a further reduction in number of live larvae by 3 -week stored $H$. megidis applied at $25 \%$ application rate (a reduction of $75 \%$ live larvae relative to control). When $H$. megidis was applied at $50 \%$ application rate the stored and unstored nematodes performed equally well, reducing the number of live weevils to about 1.5 per pot ( 82 and $84 \%$ reduction relative to control, respectively).

\section{Discussion}

These experiments show that conditioning - storing nematodes at $9{ }^{\circ} \mathrm{C}$ for 3-6 weeks prior to application - improves the performance of $S$. carpocapsae, as shown previously for $H$. megidis (Fitters et al., 2001). The inclusion of $H$. megidis in the current work allows a comparison to be made between the two species (between experiments 1 and 2, and within experiment 3). In the constant $9{ }^{\circ} \mathrm{C}$ experiments with potted ornamentals, a similar pattern was observed for the two species: unstored nematodes did not reduce 


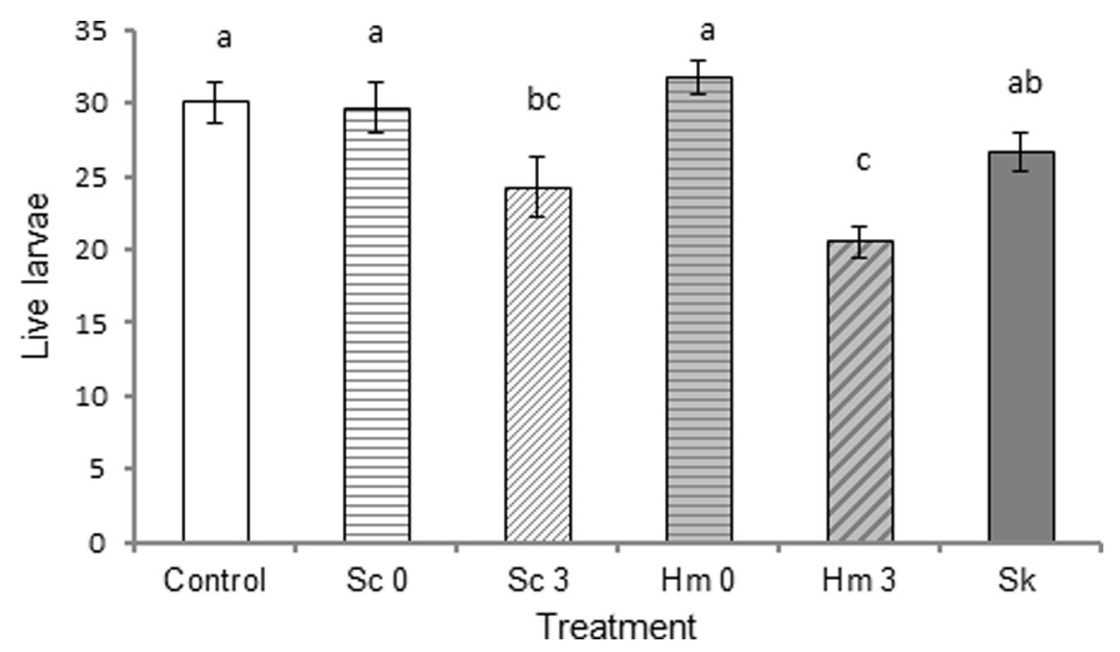

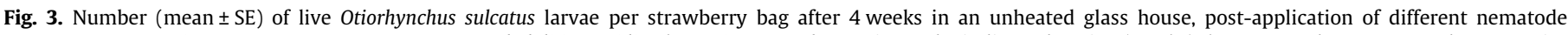

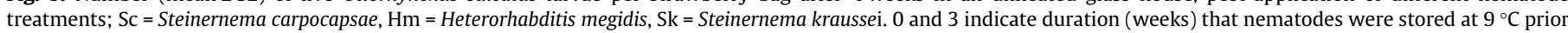

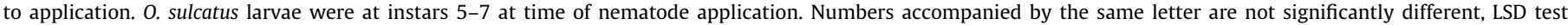
$(\alpha=0.05)$.

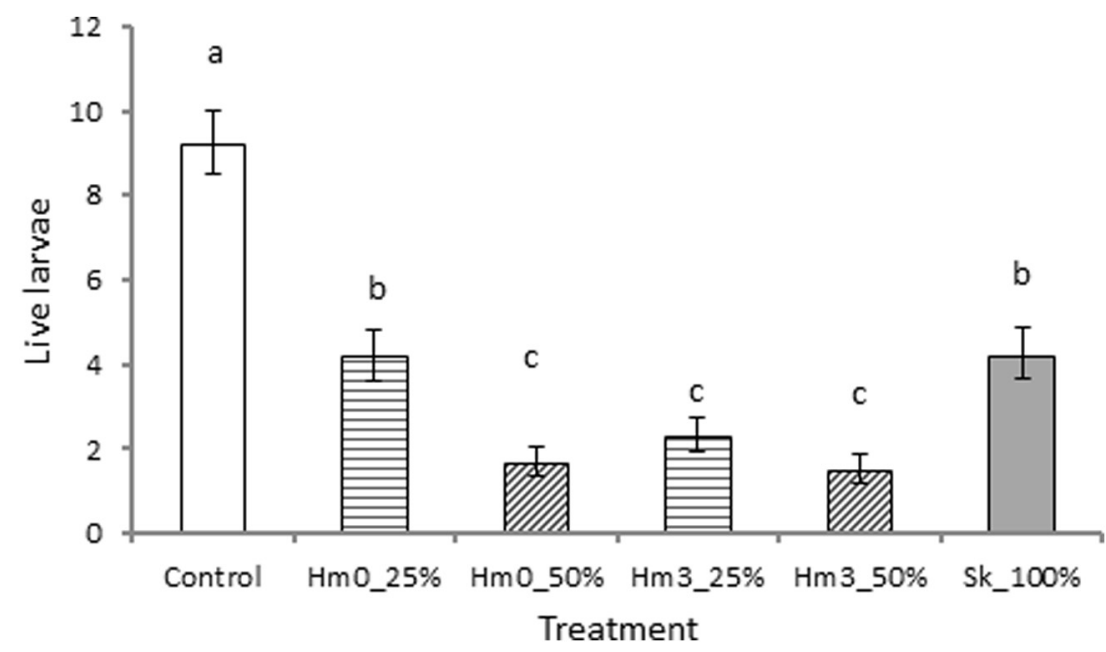

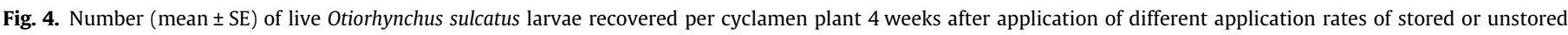

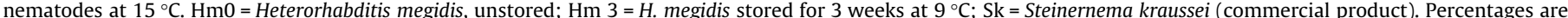

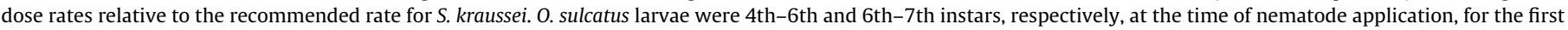
and second runs of the experiment. Numbers accompanied by the same letter are not significantly different, LSD test ( $\alpha=0.05)$

the number of live larvae relative to untreated controls, while nematodes conditioned for either 3 or 6 weeks caused a reduction. Similarly, in experiment 3 , a reduction in number of live weevils relative to control was shown for 3-week conditioned $S$. carpocapsae and $H$. megidis, but not for unstored ones. Although this experiment in strawberries was not repeated, the trend observed was the same for both nematode species, and reflected that seen in experiments 1 and 2 .

The primary aim of experiments 1-3 was to demonstrate "proof of concept", that conditioning S. carpocapsae by storage can improve its ability to suppress a pest such as vine weevil under challenging conditions of low temperature. In experiments 1 and 2 , we found no difference between nematodes conditioned for 3 or 6 weeks, either for $S$. carpocapsae or $H$. megidis. Similarly, Fitters et al. (2001) found no difference between $H$. megidis stored at $9{ }^{\circ} \mathrm{C}$ for 4 and 6 weeks storage, but a large increase from 0 to 2 and from 2 to 4 weeks storage. In Fitters' experiments, longer storage up to 12 weeks resulted in a further improvement of $H$. megidis performance over that seen after 4-6 weeks storage. Laboratory assays mirror this effect for both species, but indicate that for $S$. carpocapsae the gain due to more prolonged storage is less than for H. megidis (Guy, Gaffney, Griffin, unpublished data). The similarity between 3 and 6 weeks storage in experiments 1 and 2 here justifies the inclusion of a single storage time, 3 weeks, in later experiments, especially as our objective was not to identify optimum storage conditions, but to investigate the range of conditions under which the effects of conditioning could be detected.

In addition to temperature, plant type may also affect the success of EPN against black vine weevil (van Tol and Raupp, 2005). The more complex root system of strawberry plants may make it more difficult for EPN to find their hosts than the restricted roots of potted plants used in our other experiments. Experiment 3 provides evidence that conditioning by storing IJs at $9{ }^{\circ} \mathrm{C}$ for 3 weeks also improved performance of both $S$. carpocapsae and $H$. megidis against vine weevil in strawberry plants at temperatures ranging from 0 to $12^{\circ} \mathrm{C}$ but mainly below $10^{\circ} \mathrm{C}$, a combination of plant and temperature conditions that are more challenging than those conducted in pots at constant $9{ }^{\circ} \mathrm{C}$. Moreover, the conditions of 
Experiment 4 shows that conditioning $H$. megidis by storing IJs for 3 weeks at $9{ }^{\circ} \mathrm{C}$ improves their efficacy not just at $9{ }^{\circ} \mathrm{C}$, but also when applied at the more permissive temperature of $15^{\circ} \mathrm{C}$. Conditioned $H$. megidis IJs applied at $25 \%$ the recommended rate suppressed the weevils to the same level as unstored $H$. megidis IJs applied at 50\% rate, suggesting that conditioning can compensate for a reduced application rate. Thus, the effect of conditioning by storage at $9{ }^{\circ} \mathrm{C}$ is not restricted to low temperatures, but is also detectable at $15^{\circ} \mathrm{C}$.

There was a significant interaction between treatment and "runs" (experimental trials with advancing age of larvae) in experiment 1 (S. carpocapsae with S. kraussei as industry standard) but not in experiment 2 ( $H$. megidis with $S$. kraussei as standard). There was a notable trend for the number of live larvae to increase from run A (2-3rd instars) to D (6-7th instars) in the S. kraussei treatment of experiment 1 and, to a lesser extent, in the $S$. carpocapsae treatment, despite a concomitant decline in number of live larvae in the untreated controls. This difference between the two species in their capacity to suppress progressively older larval instars of vine weevil resulted in a closing of the gap between the two species across runs, such that there was a significant difference between them in the early runs ( $A$ and $B$ ) but not the later ones ( $C$ and $D$ ). The results of experiment 1 suggests that the efficacy of $S$. kraussei is more affected by instar stage of $O$. sulcatus present, and that the species is more effective against early rather than late instar larvae. While other factors, such as nematode quality, may also have varied between runs, $S$. kraussei has previously been shown to be more effective against early rather than late instars of O. sulcatus: in bioassays at $6^{\circ} \mathrm{C}$, S. kraussei L137 killed $79 \%$ of "small" larvae but was ineffective against "large" larvae (Long et al., 2000). These authors also reported that at $10^{\circ} \mathrm{C}$, both $S$. kraussei and $H$. megidis killed a higher percentage of small than of large larvae. That a similar effect was not detected in experiment 2 , in which $H$. megidis was tested along with $S$. kraussei, may reflect the fact that this trial did not include such early instar larvae as experiment 1 ; moreover, different plant species were employed in the two experiments, which may have influenced the differential susceptibility of vine weevil instars to nematodes. However, inspection of the data for individual runs of Experiment 2 (not shown) indicated a similar trend for an increase in number live larvae in the $S$. kraussei treatment and a closing of the gap between results for the two species with advancing larval stage. Differences in susceptibility of $O$. sulcatus instars to EPN seem to vary both depending on nematode species and on test conditions (bioassay, pot, field) (Georgis and Poinar, 1984; Long et al., 2000; van Tol and Raupp, 2005). While the early instars may be more susceptible to species such as $S$. kraussei, they may be more difficult to find in more complex field conditions, due to both their smaller physical size (Lola-Luz et al., 2005) and smaller "active space" of stimuli (Griffin, 2015).

Nemasys L, commercially produced and formulated nematode product incorporating the cold-active species $S$. kraussei, was used as a standard in all experiments. As expected, S. kraussei performed well at constant $9{ }^{\circ} \mathrm{C}$, reducing the number of live weevil larvae by $55-93 \%$ relative to the untreated control, a performance superior to that of conditioned $H$. megidis across all four runs of experiment 2 , and better than conditioned S. carpocapsae in the first two runs of experiment 1 , where early instar larvae $O$. sulcatus were present. Surprisingly, however, in experiment 3, another low temperature $\left(0-12{ }^{\circ} \mathrm{C}\right)$ experiment, the number of live larvae in the $S$. kraussei treatment did not differ to that in the control, in contrast to the two conditioned nematode treatments. One factor that may contribute to the lack of control by $S$. kraussei in this experiment is the age of the vine weevil larvae, which were 5-7th instars. As noted above, larger larvae may present a more challenging target for EPN, particularly S. kraussei. However, even when later instar larvae were present in experiments 1 and $2, S$. kraussei tended to be more effective than conditioned nematodes of the other two species. Experiment 3 was conducted in strawberries in grow bags, a more challenging arena than the pots of experiments 1 and 2 . Complex plant $\times$ EPN species interactions have been noted in vine weevil control (van Tol and Raupp, 2005), and such interactions may also play a role in reversing the control success of S. kraussei relative to the other two species in Experiment 3.

Where temperatures are not limiting, Heterorhabditis spp. are acknowledged to be highly effective against vine weevil (van Tol and Raupp, 2005). In our $15{ }^{\circ} \mathrm{C}$ experiment (expt. 4), even unstored H. megidis at $50 \%$ the recommended rate was superior to S. kraussei applied at full rate. The superiority of $H$. megidis over S. kraussei against vine weevil at permissive temperatures has previously been noted in field-grown strawberries in Norway, when spring temperature was unseasonally high (Haukeland and Lola-Luz, 2010) and has also been detected in bioassays against the large pine weevil Hylobius abietis (Coleoptera, Curculionidae) (Dillon and Griffin, unpublished data). Thus, while S. kraussei is clearly the nematode of choice for vine weevil control at temperatures of $9{ }^{\circ} \mathrm{C}$ and lower (especially when applied against young larvae), $H$. megidis is superior at higher temperatures, such as $15^{\circ} \mathrm{C}$.

In conclusion, we have demonstrated that representative species of the two main families of entomopathogenic nematodes, Heterorhabditidae and Steinernematidae, can be conditioned by appropriate storage conditions, resulting in improved control of an important pest across a range of conditions, including but not restricted to challenging conditions of low temperature. Earlier work (Griffin, 1996; Fitters et al., 2001) indicates that conditioning may comprise a general, temperature-independent maturation effect (as demonstrated by the improved efficacy at $15^{\circ} \mathrm{C}$ of $9{ }^{\circ} \mathrm{C}$ stored $H$. megidis) and a temperature-specific acclimation effect. The effect of conditioning may be less evident when test conditions are favorable - for example, a difference between conditioned and unstored $H$. megidis was not detectable in the $15{ }^{\circ} \mathrm{C}$ trial (experiment 4) when nematodes were applied at 50\% recommended rate, but conditioning may allow (and be detected when) a lower application rate to be used, as seen in that trial at $25 \%$ recommended rate. Our experiments were done with nematodes produced in insects and stored in water - conditions very different from those of commercial nematode production (Shapiro-Ilan et al., 2012). Further work is required to elucidate the nature of the changes brought about by storage, and to ascertain whether these effects could either be induced in bioreactor-produced nematodes and retained during formulation and shipping to the grower, or induced prior to application.

\section{Acknowledgments}

The research was funded by a Teagasc Walsh Fellowship and by an Irish Research Council for Science, Engineering and Technology (IRCSET) Fellowship to Adam Guy. We are grateful to Becker Underwood (UK) for supply of nematodes.

\section{References}

Bal, H.K., Michel, A.P., Grewal, P.S., 2014. Genetic selection of the ambush foraging entomopathogenic nematode, Steinernema carpocapsae for enhanced dispersal and its associated trade-offs. Evol. Ecol. 28, 923-939.

Crawley, M.J., 1993. GLIM for Ecologists. Blackwell Science, Oxford.

Fan, X., Hominick, W.M., 1991. Effects of low storage temperature on survival and infectivity of two Steinernema species (Nematoda: Steinernematidae). Rev. Nematol. 8 (2), 165-170, 14, 407-412.

Fitters, P.F.L., Dunne, R., Griffin, C.T., 2001. Improved control of Otiorhynchus sulcatus at $9^{\circ} \mathrm{C}$ by cold-stored Heterorhabditis megidis UK211. Biocontrol Sci. Technol. 11, $483-492$.

Gaffney, M., 2012. Use of novel control strategies for black vine weevil (Otiorhynchus sulcatus) populations in ornamental and soft fruit nurseries (Ph. D. Thesis). University College Dublin. 
Georgis, R., Poinar Jr, G.O., 1984. Greenhouse control of the black vine weevil Otiorhynchus sulcatus (Coleoptera: Curculionidae) by heterorhabditid and steinernematid nematodes. Environ. Entomol. 13, 1138-1140.

Georgis, R., Koppenhofer, A.M., Lacey, L.A., Belair, G., Duncan, L.W., Grewal, P.S., Samish, M., Tan, L., Torr, P., van Tol, R., 2006. Successes and failures in the use of parasitic nematodes for pest control. Biol. Control. 38, 103-123.

Griffin, C.T., Downes, M.J., 1994. Recognition of low-temperature infective isolates of the entomopathogenic nematode Heterorhabditis spp. (Rhabditida: Heterorhabditidae). Nematologica 40, 106-115.

Griffin, C.T., 1996. Effects of prior storage conditions on the infectivity of Heterorhabditis sp. (Nematoda: Heterorhabditidae). Fundam. Appl. Nematol. 19, 95-102.

Griffin, C.T., 2015. Behaviour and population dynamics of entomopathogenic nematodes following application. In: Campos-Herrera, R. (Ed.), Nematode Pathogenesis of Insects and Other Pests. Springer, London, pp. 57-95.

Haukeland, S., Lola-Luz, T., 2010. Efficacy of the entomopathogenic nematodes Steinernema kraussei and Heterorhabditis megidis against the black vine weevil Otiorhynchus sulcatus in open field-grown strawberry plants. Agric. Forest Entomol. 12, 363-369.

Koppenhöfer, A.M., Ebssa, L., Fuzy, E.M., 2013. Storage temperature and duration affect Steinernema scarabaei dispersal and attraction, virulence, and infectivity to a white grub host. J. Invertebr. Pathol. 112, 129-137.

Lacey, L.A., Grzywacz, D., Shapiro-Ilan, D.I., Frutos, R., Brownbridge, M., Goettel, M.S. 2015. Insect pathogens as biological control agents: Back to the future. J. Invertebr. Pathol. 132, 1-41.

Lola-Luz, T , Downes, M. Dunne, R, 2005. Control of black vine weevil larvae Otiorhynchus sulcatus (Fabricius) (Coleoptera: Curculionidae) in grow bags outdoors with nematodes. Agric. For. Entomol. 7, 121-126.

Long, S.J., Richardson, P.N., Fenlon, J.S., 2000. Influence of temperature on the infectivity of entomopathogenic nematodes (Steinernema and Heterorhabditis spp.) to larvae and pupae of the vine weevil Otiorhynchus sulcatus (Coleoptera: Curculionidae). Nematology 2, 309-317.

Moorhouse, E.R., Charnley, A.K., Gillespie, A.T., 1992. A review of the biology and control of the vine weevil, Otiorhynchus sulcatus (Coleoptera, Curculionidae) Ann. Appl. Biol. 121, 431-454.

Nimkingrat, P., Khanam, S., Strauch, O., Ehlers, R.U., 2013. Hybridisation and selective breeding for improvement of low temperature activity of the entomopathogenic nematode Steinernema feltiae. BioControl 58, 417-426.

Salame, L., Glazer, I., Chubinishvilli, M.T., Chkhubianishvili, T., 2014. Genetic improvement of the desiccation tolerance and host-seeking ability of the entomopathogenic nematode Steinernema feltiae. Phytoparasitica 38, 359-368.

Shapiro-Ilan, D.I., Gouge, D.H., Piggott, S.J., Fife, J.P. 2006. Application technology and environmental considerations for use of entomopathogenic nematodes in biological control. Biol. Control. 38, 124-133.

Shapiro-Ilan, D.I., Han, R.C., Dolinski, C., 2012. Entomopathogenic nematode production and application technology. J. Nematol. 44, 206-217.

Smith, F.F., 1932. Biology and Control of the Black Vine Weevil. United States Department of Agriculture. Technical Bulletin No. 325.

Stenseth, C., 1979. Effects of temperature on development of Otiorhynchus sulcatus (Coleoptera: Curculionidae). Ann. Appl. Biol. 91, 179-185.

van Tol, R.W.H.M., Raupp, M.J., 2005. Nursery and Tree Application. In: Grewal, P.S. et al. (Eds.), Nematodes as Biocontrol Agents. CABI Publishing, Wallingford, UK, pp. 167-190.

Willmott, D.M., Hart, A.J., Long, S.J., Edmondson, R.N., Richardson, P.N., 2002. Use of a cold-active entomopathogenic nematode Steinernema kraussei to control overwintering larvae of the black vine weevil Otiorhynchus sulcatus (Coleoptera: Curculionidae) in outdoor strawberry plants. Nematology 4, 925-932.

Woodring, J.L., Kaya, H.K., 1988. Steinernematid and Heterorhabditid Nematodes: A Handbook of Techniques. Arkansas Agricultural Experimental Station, Fayetteville. 